\title{
China as a Subject of International Education: Experience of Development
}

\author{
Chengzhang Zou \\ Ph.D., Associate Professor, Guangdong University of Petrochemical Technology \\ (Maoming, China) \\ E-mail: 787234243@qq.com \\ https://orcid.org/0000-0002-6425-3811

\section{Weizhen Gao} \\ Ph.D. student, National Pedagogical Dragomanov University (Kyiv, Ukraine) \\ E-mail: gaokyiv@gmail.com \\ https://orcid.org/0000-0003-2233-387X
}

\begin{abstract}
The phenomenon of internationalization of the space of modern higher education is carried out as basic of the research. Its specific features are distinguished at the contemporary stage of social development. The idea of international education is grounded as a way of formation of cosmopolitanism. The authors examine the positive experience of China in the internationalization of the country's higher education system through the introduction of technical and pedagogical innovations, distance education, the development of language competences and consistent social and educational policies.

Keywords: international education; distance education; academic mobility; internationalization of higher education; world market of educational services
\end{abstract}

Received: November 29, 2018; accepted: December 24, 2018

Future Human Image, Volume 11, 2019: 120-129.

https://doi.org/10.29202/fhi/11/14

\section{Internationalization of education: conceptual analysis}

The modern world is rapidly developing, both in scientific and educational and in technical and industrial terms. In view of these changes, the scale of the so-called "intellectual migration", which includes the concept of academic mobility, the concept of labor migration, grows [Savenkova \& Svyrydenko, 2018]. Conceptually, this phenomenon is revealed in two directions of interpretation: the exchange of knowledge and experience, or the search for the most favorable conditions for professional self-realization, which is absolutely a natural

(C) Zou, Chengzhang, 2019

(C) Gao, Weizhen, 2019 
phenomenon of the modern information-unified world. Another view of this problem includes a negative assessment of the phenomenon of intellectual migration, namely the outflow of the intellectual elite, the most productive labor of a particular country or region. The negativity of this assessment is based on the potential decrease of the rates of socio-economic development of the country from which experienced experts migrate and the logical further decrease in its level of living, social security and the content and quality of education and science.

This spontaneous phenomenon with the rest acquires a systemic and mass character, which is called the internationalization of education. The problem of the formation and functioning of international education is researched by numerous authors. Therefore, Nicholas Tate analyzes the problem of international education in its retrospective of the twentieth century [Tate, 2013]. The author distinguishes the following levels of analytics: the main views on internationalism, the characteristics of the virtues of a worthy person as an ideal of education and a system of pedagogical principles based on a survey, cooperation and debate. The author also illustrates the transformation of the education system from a closed to an open, global character. The general context of the internationalization of education, the author considers the key features of the project of the Enlightenment, whose introduction of ideas, as well as attempts to rebut it, has created a multipolar world that requires a universal educational program.

Larissa Titarenko and Craig B. Little describe an experiment in shaping the international experience and intercultural competencies required in the global market [Titarenko \& Little, 2015]. The authors articulate the problem of learning by means of an international online program. In the course of its implementation, they conclude that learning in the "virtual classroom" provided that they are physically absent in the classroom are not only able to effectively master the necessary competencies, but also to establish successful asynchronous communication between the participants in the educational process. Thus, pedagogical technologies and practices of distance learning are effective both in establishing feedback with students, and in the formation of emotional intelligence, and in terms of the formation of multicomponent cooperation between participants in the educational process.

Mim Fox, who studies the principles of social work in various aspects of communicative space, focuses on the problem of establishing communication in the space of international education [Fox, 2017]. Thus, the researcher distinguishes five "lenses of distance", through which deepening students' understanding: geographical, cultural, emotional, pedagogical and technological distances. Taking into account these trajectories of communicative activity of the participants of the educational process allows controlling and maintaining positive motivation for training and pedagogical activity. It is worth noting the importance of engaging in the creation and improvement of the common educational space of various ethnic and social groups.

The problem of access to information, in general, is quite effectively solved by the wide introduction of distance education around the world, at all levels and areas of scientific interests. For example, Jim Bell with other authors is formulating questions of marketing proposals in the conditions of internationalization of the global cultural and social space [Bell et al., 2001]. Therefore, there is a growing interest in distance learning in distributing and manipulating such offers. The authors convinced that the latest information technologies provide significant opportunities for the internationalization of economic education and, ultimately, an increase in the efficiency and creativity of marketing services. Alternatively, Tony Bates describes the international online programs at the University of British Columbia (UBC) in Canada in association with the Monterrey Institute of Technology in Mexico 
[Bates, 2001]. The author investigates the problem of cooperation in view of various cultural and pedagogical peculiarities of the educational context. In addition, such projects can be massive and successful. Therefore, George M. Flattery describes the project Global University as an international school with a network of offices in 169 countries of the world [Flattery, 2002]. This educational conglomerate provides educational services to a wide range of student audiences and introduces a variety of techniques and teaching styles. This educational center implements exclusively distance education, offers courses for self-study. The total number of students studying at Global University is, according to the author, 475,000 people. The specifics of these educational services are conceptually evangelical. However, the very model of such an organization of educational space is extremely promising and demanded by modern society. In accordance, Liz Thach and Karen L. Murphy study the problem of the specificity of the educational continuum at different levels of interaction of separate structures in the implementation of distance learning [Thach \& Murphy, 1996]. The authors work out the main cross-cutting components of distance education and actualize the problem of management, internal policy of higher education and incentive systems in the implementation of the general principles of distance education. In their view, education is a factor in consolidating people on the principles of cosmopolitanism: "Few people, however, were able to predict the turbulence that would be created by weaving course development processes, students at distant sites, classes, and institutions around the world into the web of technology. Suddenly, separate cultures, laws, regulations, and customs have been brought together in a kaleidoscope of learning. The result is chaotic, fun, challenging, and anxiety-producing; it challenges all of those who work in the field of distance education to broaden their perspectives, to strive for the implementation of best practices; and to encourage collaboration while respecting individual, group, and institutional integrity" [Thach \& Murphy, 1996: 17].

Or another way of such internationalization and universalization of education offer Daniel Villar-Onrubia and Brinder Rajpal emphasize the definition of virtual mobility as the most flexible, universal and inclusive technology in providing international educational services and advanced international experience [Villar-Onrubia \& Rajpal, 2016]. Academic mobility, which involves travelling abroad for the purpose of education, does not solve the urgent need for modernization of the content and system of education of individual countries. Referring to the Coventry University Virtual Mobility Scheme, the author points out the need for interaction between students and specialists in solving individual problems and challenges of production activity, which greatly improves and develops the key competencies of educators. The authors note: "Moreover, the link between IoC and intercultural competence development is not always easily constructed without appropriate support, capacity-building or the internationalising of educators themselves. Despite the growing breadth of internationalisation initiatives, efforts do not always translate easily into meaningful teaching and learning interventions for the diverse modern-day classroom. Certainly, it is not always easy for some lecturers to define or interpret the relationship between their subject and internationalisation without appropriate and practical support that is pertinent to their teaching contexts, though access to such training is often limited and/or far from where academics live and thrive" [Villar-Onrubia \& Rajpal, 2016: 4]. The authors analyze in detail the role of the main participants in this interaction, the specificity of cooperation and factors of political, technological, social and other means of influence.

That is why the authors insist: "Only by providing academic staff with relevant resources and training opportunities will universities be able to provide meaningful and sustainable international experiences, whether they are ICT-enabled or not" [Villar-Onrubia \& Rajpal, 
2016: 7]. However, the space of international education promotes, among other things, the rapid growth of virtual technologies. And this leads to a new problem: the ways of the orientation of a person in the modern information field. Namely, Shiguang Qiu, Qichang He, Xiumin Fan and Dianliang Wu explore ways and trajectories of human movement in virtual cyberspace [Qiu et al., 2014]. They distinguish three types of movement: primitive, precise and transitive. The regulation of the specificity and technology of human orientation in the virtual space is important in terms of optimizing the main activities related to education, science and production: "Some distance learning schools are primarily contained in one location and work out of that office to reach students everywhere. Global University has a landed network of offices in over 150 countries. This means that most students usually are not too far from someone with whom they can meet face-face. The Internet now has greatly increased opportunities for interaction" [Qiu et al., 2014: 31]. The determining factor for the success of this work is the authors of the parameterized models of the semantic level, which include technical attributes as derivatives of the original semiotic model.

Hence, the internationalization of higher education acquires at the present stage peculiar features of the specification.

The economic principle of internationalization. Interaction at the international level in the field of education is traditionally interpreted as the development of intercultural communication and cooperation. Valuable accents of cooperation in education are motivated by the economic levers of modern society: state management for attracting foreign students as an important element of filling the budget of the country, introducing pedagogical and technical innovations into the educational process with the purpose of expanding the number of applicants of education, developing partnerships between separate regions and countries with the aim of The unification of efforts before the challenges of the social sphere and the technological process.

The growth of competition in the world market of educational services. Education in modern society is not only an essential element of cultural broadcasting but also a significant factor in the link between scientific and technological innovations and their introduction into production and life. Indeed, the intermediate position of education between science and production reinforces the importance of educational activity at all levels of the functioning of modern society. However, it should be remembered that education in modern communicative discourses often endangers manipulative practices. Therefore, there is a need for the training of the relevant specialists of information influence, and the formation of a wide range of information security competence.

The development of information and communication technologies stimulates competition between individual countries, regions and educational institutions-exporters of educational services. Such factors influence the content of the educational process, it's means and timing. First, the content of education is increasingly specialized, narrowing. Secondly, there is a worldwide tendency to reduce the terms of the training courses, to accelerate the development of the necessary theoretical and practical provisions. New teaching strategies are also introduced: design thinking and higgogistics, training and distance learning programs, mixed courses, a combination of training and work. The existence of transnational corporations and the globalization of the global economy lead to the mobility of capital, goods and services, the location of production, and, accordingly, the specialists involved in this process. Therefore, with the necessity of forming a common space of higher education, with the general recognition of basic educational competence, the unified content of the educational standard and the system of certification and accreditation, governing the educational sphere of various national states. 
Exceeding national states and governments is legalized in the form of autonomy of institutions of higher education, therefore the modern university is a trademark, a brand requiring a corresponding set of organizational and managerial measures and strategies. It is logical that, besides purely educational tasks, educational establishments with the need to determine and resolve economic priorities and problems. Internationalization in this context is a guarantee of the effective functioning of the university. The formation of the information society and the acceleration of the pace of civilization development lead to the need to understand education as a prolonged, permanent state of a modern specialist. The reorientation of educational programs and courses to professional, rather than age, in education, is a significant phenomenon. After all, competence and experience as the necessary preconditions for the image of a specialist are measured by success, qualitative indicators, rather than quantitative indicators of the time spent.

\section{China's state education policy in the process of internationalization}

The system of higher education in China is shaped by the uniqueness of the socio-cultural foundations and the specifics of historical development. However, avoiding the globalization of the global economy would be an archaic and inappropriate strategy. Therefore, the Chinese government is implementing the policy of the "golden mean" both in terms of economic development and growth, and in solving social problems such as education. Its purpose is to preserve national traditions and ideological values, along with organic interaction with the best examples of world progress. Therefore, in 2003, the government allowed the creation of joint educational institutions with foreign educational institutions. Only over a year, the number of such joint projects was more than 700 programs [Ennew \& Yang, 2009: 23]. This amount is due to the general increase in the social standards of the Chinese republic since the profits of a large number of Chinese families have allowed investing in the education of children both inside and outside the country. In the future, this trend is only rising: in 2007, 144,000 Chinese students received higher education in foreign universities, according to the forecasts of the Ministry of Education of China, this number will be 200 thousand people starting in 2010, and 300 thousand people starting in 2020 [Xiaohao et al., 2009: 11]. It is natural that the Chinese government takes the necessary measures of state support to national educational institutions. Thus, according to Project 211, the top 100 universities in China that received priority funding were recognized in 1993; and project 985, adopted five years later, seeks to internationalize 43 of the best Chinese universities, increasing their competitiveness in the global educational services market.

Hence, the internationalization of higher education in China requires the introduction of modern pedagogical and technical innovations. Therefore, Runfang Wei argues that distance and open education is an innovation of Western culture and democratic societies in Western countries [Wei, 2010]. However, the author believes that the direct introduction of such an experience in the educational system of the Chinese Republic is not feasible. Distant and open education is undoubtedly demanded by modern Chinese society, where the relevant political, social, economic and cultural context has a significant meaningful impact. Accordingly, the theory and practice of distance and open education interact with each other, modifying the main strategies of theoretical generalizations and pragmatic implementations. However, it should be remembered that the way of interaction in a virtual environment, such as distance education, significantly affects the general logic of personality activity: "As distance education embraces 
open learning to promote a learning society, the underpinning ideas of distance education that is, educational democracy, equity and egalitarianism — should be revisited. These ideas are the inspiration for the creation and development of distance education and, together with the successful operation of ODL, have taken distance education from 'back-door learning' to 'front-door learning' in many developed countries as more and more traditional educational organizations find fewer philosophical and practical concerns with delivering education at a distance. The practice and activities of distance education in developing countries may not demonstrate all these ideas, but the review of these ideas might not only create an awareness of greater equity but also encourage more educational democracy in both developed and developing countries. Moreover, these ideas can be made compatible with the concepts of open learning so as to build a global learning society for all" [Wei, 2010: 54]. Therefore, there are grounds to argue that the internationalization of education contributes to the promotion of democratic principles of liberalism and the personalization of responsibility for the consequences of collective action. This aspect is extremely important at the present stage of world civilization. After all, there is a need for humanity to learn to interact in such a way that the discourse on responsibility was truly universal. An example of such an organization is described at a much more local level: the authors analyze the University of Hong Kong as a significant virtual learning environment, the principles of organization and operation of which greatly transform the traditional notion of the educational space [Hu et al., 2011]. Among other things, this innovative way of organizing learning involves taking into account the social determinants of education. The University of Hong Kong introduces such education management, which enhances the activity of educators, namely: collaborative modeling of the educational process, group learning, geo-co-operation principles, socially oriented norms of knowledge and digital technology of virtual space development. All these innovations provide a wide range of opportunities for stimulating interdisciplinary cooperation, updating education management models, and implementing scientific concepts in education and production.

However, not all researchers share such an optimistic view on the introduction in China of the principles of internationalization and virtualization of education. Alison A. CarrChellman and Ke Zhang note that China has a long and meaningful history of using distance learning [Carr-Chellman \& Zhang, 2000]. However, the active formation of an online learning environment causes a number of challenges for the Chinese state. Therefore, there is a need for a thorough analysis of relevant political rhetoric, market status of education, open access to educational resources, power issues, adaptation and globalization. Therefore, "The motives for Chinese distance education expansion and funding are quite different from those of the US. While some facets of the movement are similar to our own experiences of distance learning, the motive seems to be strongly rooted in the ability of the government to educate adequately large masses of people (as opposed to trying to make a pro from these learners)" [Carr-Chellman \& Zhang, 2000: 306]. The authors conclude that the implementation of distance learning in China requires a balanced and consistent approach.

Differentiation of such approaches as methods of interaction offers Junhong Xiao, which conceptually substantiates the content and principles of distance learning and its role in the modern global educational space [Xiao, 2018]. The author outlines three types of convergence of distance education and campus-based learning: dual mode, adding / mixing and full convergence as the most complex and little implemented. Also, the author concludes that distance learning in the modern world has become as traditional as the study of the campus. A quite controversial position of the author. Therefore, Qing Chen and Santosh 
Panda analyze the problem of the openness of educational resources and appropriate open licensing, which greatly increases the total number of users of educational services and the entities that provide them [Chen \& Panda, 2013]. For modern China, this problem is of particular importance both at the local professional level and at the state level. The authors rely on the results of a survey conducted among the teachers of the Open University of Beijing on four parameters: awareness, needs, application and limitations. As a result, the authors received the following indicators: the level of knowledge about the possibilities of distance learning among teachers was high enough, but the idea of the possibility of their use were often fragmentary or false. Therefore, the perspective of assessing the needs of teachers in distance learning technologies is difficult for researchers to verify in a coherent system. It is natural that the use of distance learning technology is also distinguished by its creativity and originality. The main limitations of this practice were the teachers referred to the problems of orientation in the online education space, copyright protection, the general management system. Therefore, we consider it appropriate to note that distance education is a promising direction for the development of the educational process in accordance with the challenges of modern society. However, will not the state lose its unique ethnic and cultural peculiarities on the way of such unification of the educational space? Unofficially, the universal language of world communication is English. Nevertheless, language and thinking are closely linked, and the use of individual linguistic tools and structures significantly affects the attitude and reflection. However, is it possible to avoid this linguistic expansion? Tao Xiong and Anwei Feng actualizing the problem of studying English in modern China as a way of international communication [Xiong \& Feng, 2018]. The authors refer to numerous empirical material: interviews, observations, documentary information and test results. Thus, a significant role in improving the efficiency of learning English as a second is to take into account the cultural and educational context, especially with the wider introduction of the model of bilingual education in China. The number and distribution of these programs are due to public demand. In accordance, Shuning Liu reveals the problem of the growth of the number of Chinese schoolchildren drowning to study at US universities under the new international educational programs [Liu, 2018]. The author notes that the high cost of these programs creates unequal access to international education. The problem field of the author's research is comparing network connections as a way to open networks of social actors, ways of interaction and power relations. The privatization of education and the sovereign power of the Chinese state to some extent contradicts the neoliberal principles of educational practices and pedagogical technologies.

However, the Chinese government seeks to balance these contradictory trends in the interaction of the national education system and the world market of educational services. Li Fengliang reveals the essence of the debate on financing higher education in China, based on the implementation of a cost-sharing model [Fengliang, 2012]. According to this funding model, students were required to pay for their studies. Therefore, the leadership of the state introduced a policy of a coherent financial commitment on the cost of education. In addition to theoretical analysis, the author gives a number of recommendations for strengthening the financial basis for the development of higher education in China. This policy is very productive, as evidenced by the numerical statistics provided above. Details of the content and implementation of this policy are reported Shuangmiao Han and Fugui Ye, who study the problem of a political network approach that is widely used in modern state governance [Han \& Ye, 2017]. The authors use the conceptual framework of the political network and 
the category of references to observing the evolution of policy in the education of China. The authors refer to China's National Plan for Medium and Long-Term Educational Reform and Development (2010-2020). Researchers note the fundamental transformations of China's educational policy: first, a tangible transition from the practice of party dominance to the practice of managing the central government; and secondly, the strengthening of the role of higher education institutions and academics as a group of specialists; and thirdly, the growing role of non-governmental actors in developing educational policies. Therefore, the purpose of the study is to highlight the principles of the educational policy of modern China in view of the formation of a global educational network.

Such a strong interest in education issues by the Chinese government is socially viable and politically justifiable. For example, Xue Eryong and Zhou Xiuping raise the problem of poverty as one of the global trends of our time [Eryong \& Xiuping, 2018]. There is no doubt that the poverty line is very different in different countries: "The theoretical framework of this article is based on the notion that education policy is part of a social policy to achieve social justice. One of the most distinctive features of American social policy is the belief in the capacity of public education to redress unequal opportunity and eliminate poverty" [Eryong \& Xiuping, 2018: 5]. The authors insist on China's positive experience in combating poverty through education. The content of this experience is not in the temporal programs of social protection of the poor but in the intellectual support of a sustainable regime for the creation of the potential of the poor, and its pragmatic implementation. Mandatory nineyear education, multilevel and targeted educational policy, shifting emphasis on subsidizing education potential, including education in the national strategic plan for poverty alleviation. It is substantiated that "China's experience in the past three decades shows that education is an approach and also an objective of poverty alleviation. Overall, poverty alleviation through education has gone through three stages, with an emphasis on the elimination of illiteracy, access to education and educational equity, and quality education and targeted poverty reduction, respectively. Educational support has been one of the five targeted poverty reduction mechanisms, signifying that poverty alleviation through education has reached a new height in China's anti-poverty policy system" [Eryong \& Xiuping, 2018: 5]. The authors are convinced that the positive experience of China can serve as an example for the future of all mankind. Indeed, the effective management of internationalization of education, coupled with the prudent state policy in the field of education, brings significant results to the quality and relevance of the system of higher education in China.

\section{Conclusions}

Consequently, based on our analysis, we can state the following conclusions about how to optimize interaction in international education.

1. Investing in research activities involving a wide range of interested professionals, potential employers and performing the functions of popularizing science and education. The Chinese government is implementing long-term large-scale projects for the financing and development of education and science. These projects include expanding the potential of educators, both at the expense of the state-funded training costs and through the use of distance learning.

2. Implementation of world standards of quality certification, transparency of content and results of the educational process. It is known that China provides educational 
services to almost $10 \%$ of all foreign students in the world (). Among the world's university ratings, Asian countries, China, in particular, create significant competition for universities in Europe and the United States.

3. Encouraging and national recognition of international experience in education cooperation. Therefore, by the year 2015, the Chinese government has signed agreements on recognition of degrees and qualifications with 34 countries of the world.

4. Formation of effective communication management system in institutions of higher education with the purpose of development of diversification of export/import of educational services. Broad governmental support for language courses, both for mastering Chinese foreigners, and the creation of a two-language education system in the country.

5. Liberalization of the educational space, which would consist of its plasticity, pragmatism, innovation and inclusiveness. Some positive developments in this respect already take place in the education of China, but this principle is more likely to be the direction of possible further reforms and transformations.

\section{References}

Bates, Tony. International distance education: Cultural and ethical issues. Distance Education. Vol. 22, Issue 1, 2001: 122-136. https://doi.org/10.1080/0158791010220107

Bell, Jim, Ken Deans, Pat Ibbotson and Rudolf R. Sinkovics. Towards the "Internetalization" of International Marketing Education. Marketing Education Review. Vol. 11, Issue 3, 2001: 69-79, https://doi.org/10.1080/10528008.2001.11488758

Carr-Chellman, Alison, and Ka Zhang. China's future with distance education: Rhetoric and realities. Information, Communication \& Society. Vol. 3, Issue 3, 2000: 303-312, https://doi.org/10.1080/13691180051033199

Chen, Qing, and Santosh Panda. Needs for and utilization of OER in distance education: a Chinese survey. Educational Media International. Vol. 50, Issue 2, 2013: 77-92. https:// doi.org/10.1080/09523987.2013.795324

Ennew, Christine T., and Fujia Yang. Foreign Universities in China: a Case Study. European Journal of Education. Vol. 44, Issue 1, 2009: 21-36. https://doi.org/10.1111/j.14653435.2008.01368.x

Eryong, Xue and Zhou Xiuping. Education and anti-poverty: Policy theory and strategy of poverty alleviation through education in China. Educational Philosophy and Theory. Vol. 50, Issue12, 2018: 1101-1112. https://doi.org/10.1080/00131857.2018.1438889

Fengliang, Li. Financing higher education: lessons from China. Irish Educational Studies. Vol. 31, Issue 2, 2012: 191-206. https://doi.org/10.1080/03323315.2011.634094

Flattery, George M. Global University: its history, philosophy, mission, and international impact. Christian Higher Education. Vol. 1, Issue 1, 2002: 29-37. https://doi. org/10.1080/15363750213776

Fox, Mim. Student isolation: the experience of distance on international field placement. Social Work Education. The International Journal. Vol. 36, Issue 5, 2017: 508-520, https://doi.org/10.1080/02615479.2016.1215418

Han, Shuangmiao, and Fugui Ye. China's education policy-making: a policy network perspective. Journal of Education Policy. Vol. 32, Issue 4, 2017: 389-413. https://doi. org/10.1080/02680939.2017.1291998 
$\mathrm{Hu}$, Mingyuan, Hui Lin, Bin Chen, Min Chen M., Weitao Che and Fengru Huang. A virtual learning environment of the Chinese University of Hong Kong. International Journal of Digital Earth. Vol. 4 Issue 2, 2011: 171-182. https://doi.org/10.1080/17538947.201 0.535028

Liu, Shuning. Neoliberal global assemblages: The emergence of "public" international highschool curriculum programs in China. Curriculum Inquiry. Vol. 48, Issue 2, 2018: 203 219. https://doi.org/10.1080/03626784.2018.1435977

Qiu, Shiguang, Quichang He, Xiumin Fan and Dianliang Wu. Virtual human hybrid control in virtual assembly and maintenance simulation. International Journal of Production Research. Vol. 54, Issue 3, 2014: 867-887. https://doi.org/10.1080/00207543.2013.84 2025

Savenkova, Liudmyla, and Denys Svyrydenko. Academic Mobility and Academic Migration Issues: the Case of Ukrainian Higher Education. Interdisciplinary Studies of Complex Systems, No. 13, 2018: 57-65.

Tate, Nicholas. International education in a post-Enlightenment world. Educational Review. Vol. 65, Issue 3, 2013: 253-266. https://doi.org/10.1080/00131911.2013.785938

Thach, Liz, and Karen L. Murphy. Collaboration in distance education: From local to international perspectives. American Journal of Distance Education. Vol. 8, Issue 3, 1996: 5-21. https://doi.org/10.1080/08923649409526863

Titarenko, Larissa, and Craig B. Little. International Cross-Cultural Online Learning and Teaching: Effective Tools and Approaches. American Journal of Distance Education. Vol. 31, Issue 2, 2015: 112-127. https://doi.org/10.1080/08923647.2017.1306767

Villar-Onrubia, Daniel, and Brinder Rajpal. Online international learning. Internationalising the curriculum through virtual mobility at Coventry University. Perspectives: Policy and Practice in Higher Education. Vol. 20, Issue 2-3, 2016: 75-82. https://doi.org/10.1 080/13603108.2015.1067652

Wei, Runfang. China's radio and TV universities: reflections on theory and practice of open and distance learning. Open Learning: The Journal of Open, Distance and e-Learning. Vol. 25, Issue 1, 2010: 45-56, https://doi.org/10.1080/02680510903482199

Williams, Christopher. Global justice and education: from nation to neuron. Educational Review. Vol. 62, Issue 3, 2010: 343-356. https://doi.org/10.1080/00131911.2010.503 605

Xiao, Junhong. On the margins or at the center? Distance education in higher education. Distance Education. Vol. 39, Issue 2, 2018: 259-274. https://doi.org/10.1080/015879 19.2018.1429213

Xiaohao, Ding, Yue Changjun, and Sun Yuze. The Influence of China's Entry into the WTO on its Education System. European Journal of Education. Vol. 44, Issue 1, 2009: 9-19.

Xiong, Tao, and Anwei Feng. Localizing immersion education: A case study of an international bilingual education program in south China. International Journal of Bilingual Education and Bilingualism. Vol. 1, Issue 1, 2018: 1-10. https://doi.org/10.1080/1367 0050.2018 .1435626 